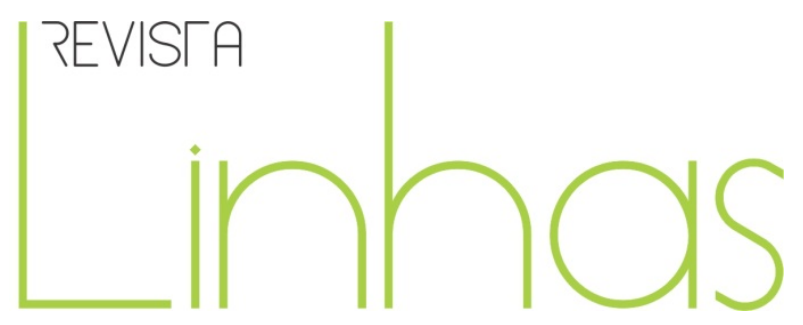

\title{
Tensões entre conhecimentos comuns e específicos no processo de escolarização de alunos com deficiência no contexto da inclusão escolar
}

\begin{abstract}
Resumo
O texto tem como objetivo problematizar alguns desafios existentes na oferta de atividades complementares ao processo de escolarização de estudantes com deficiência em processos de inclusão escolar. Discute a tensão existente na garantia do direito de apropriação do currículo comum e de conhecimentos considerados específicos, mas relevantes para o desenvolvimento do aluno e para o envolvimento nas atividades desenvolvidas na escola de ensino regular. Dialoga com diferentes teóricos da Educação e da Educação Especial e aponta alguns desafios que precisam ser superados para que não haja dicotomias e hierarquias entre conhecimentos comuns e específicos a serem apropriados por esses estudantes no contexto da Educação inclusiva. Para tal, conversa com discursos de professores em busca de sentidos instituintes de uma outra articulação com o conhecimento.
\end{abstract}

Palavras-chave: Educação especial; Currículo; Atendimento educacional especializado.
Denise Meyrelles de Jesus Doutora em Psicologia da Educação pela University of California - Estados Unidos jesusdenise@hotmail.com

\section{Alexandro Braga Vieira}

Doutor em Educação pela Universidade Federal do Espírito

Santo - UFES - Brasil allexbraga@hotmail.com

Ariadna Pereira Siqueira Effgen Doutoranda em Educação pela Universidade Federal do Espírito Santo - UFES - Brasil siqueiraariadna@yahoo.com.br

\section{Para citar este artigo:}

JESUS, Denise Meyrelles de; VIEIRA, Alexandro Braga; EFFGEN, Ariadna Pereira Siqueira. Tensões entre conhecimentos comuns e específicos no processo de escolarização de alunos com deficiência no contexto da inclusão escolar. Revista Linhas. Florianópolis, v. 16, n. 31, p. 61 - 80, maio/ago. 2015. 


\title{
Stress between common and specific knowledge in the education process of students with disabilities in the school inclusion context
}

\begin{abstract}
This article aims at questioning a few challenges arising from the offer of activities complementary to the process of education of students with disabilities during the process of school inclusion. It discusses the stress existing while ensuring the right to common curriculum and knowledge considered specific, but relevant to students' development and involvement in activities carried out in regular school teaching. The study is based on different education and special education theoreticians and it points at some challenges that need to be overcome so that there are no dichotomies and hierarchies between common and specific knowledge to be learned by these students in the inclusive school setting. In this regard, the study analyzes teachers' discourses for instituting meanings to other interaction with knowledge.
\end{abstract}

Keywords: Special education; Curriculum; Specialized education service. 
Nosso objetivo neste texto é dialogar sobre algumas tensões que temos observado na oferta de atividades consideradas complementares ao processo de escolarização de estudantes com deficiência nas escolas de ensino regular. A promoção dessa oferta ganha sustentação nos pressupostos da inclusão escolar que convoca os sistemas de ensino a implementarem políticas públicas para que seja garantido o direito de apropriação dos conhecimentos praticados nos currículos escolares, mas também dos saberes específicos por serem também considerados relevantes para o desenvolvimento do estudante e para a apropriação do currículo comum.

Não desejamos aqui constituir uma definição fechada do que possa ser considerado como conhecimentos específicos, pois essa necessidade se dá considerando as condições vividas pelos alunos em seus processos de escolarização, bem como de acordo com os contextos sociais nos quais habitam. Gostaríamos de tomar alguns exemplos, relembramos o domínio do código Braille, do sorobã e de conhecimentos de orientação e mobilidade para estudantes cegos; a apropriação da Libras como língua materna e do Português escrito como segunda língua para educandos surdos; a língua de sinais táteis para sujeitos com surdocegueira e da comunicação alternativa para indivíduos sem fala articulada. Ou como sinaliza a Política Nacional de Educação Especial em uma perspectiva inclusiva de 2008: programas de enriquecimento curricular, o ensino de linguagens e códigos específicos de comunicação e sinalização e tecnologia assistiva.

Nesta mesma linha de pensamento, nos desafiamos a romper com a ideia de currículo como uma lista de conteúdos e conhecimentos elencados em livros didáticos que, muitas vezes, são seguidos à risca no processo de escolarização dos estudantes. Afastamo-nos também da ideia de currículo como um conjunto de conhecimentos didatizados que não se relacionam com o desenvolvimento humano e sim com a manutenção de uma organização social que dita para a escola o que deve ser ensinado para a preservação do status quo de determinados grupos sociais. 
O objetivo da educação diz respeito, de um lado, à identificação dos elementos culturais que precisam ser assimilados pelos indivíduos da espécie humana para que eles se tornem humanos e, de outro lado e concomitantemente, à descoberta de formas mais adequadas para atingir esse objetivo. (SAVIANI, 2003, p. 13)

Quando fazemos do currículo uma lista de conhecimentos definidos a priori, uma relação hierárquica entre conhecimentos e uma sequência de saberes que determina o que friamente será ensinado, perdemos o sentido da escola. Muitas vezes, essa concepção de currículo produz a ideia de que o estudante com deficiência não tem capacidade e necessidade de se apropriar dos conhecimentos e experiências historicamente acumulados e intimamente relacionados ao desenvolvimento do humano. Para Meirieu (2002), o conhecimento explorado na escola tem o objetivo de produzir o vínculo entre a pessoa e a sociedade. Vínculo esse traduzido na capacidade de o sujeito se humanizar e de lançar um olhar crítico-reflexivo sobre a sociedade na busca por mudanças para as situações excludentes e desafiadoras.

Essa reflexão nos faz refletir que uma coisa é pensar o ensino da Língua Portuguesa como um conjunto de regras voltadas para um trabalho de metalinguagem. Outra coisa é assumir a apropriação da linguagem como uma ferramenta que nos permite expressar nossas vivências, crenças, sentimentos, desejos e as interpretações que fazemos dos universos sociais constituídos. A linguagem tem um papel fundante na construção da singularidade de cada pessoa e na constituição de marcas de pertencimento a um determinado grupo social (GOULART, 2006).

Isso nos permite entender que o currículo não se resume a um programa ou elenco de disciplinas. Trata-se de conhecimentos que possibilitam a produção de sentidos, ideias, conceitos, valores, símbolos, hábitos, atitudes e novos conhecimentos. Nesse movimento, o desafio não é resumir o ensino da Matemática como com conjunto de operações, símbolos e fórmulas que devem ser assimiladas pelo estudante. Ao contrário, a questão é dar sentido à aprendizagem matemática no contexto de sua aplicação, no contexto histórico de sua construção e no envolvimento do aluno com a construção do conhecimento.

Nesta mesma linha de raciocínio, buscar outros sentidos para a apropriação dos 
conhecimentos nas Artes, na Geografia, nas Ciências Humanas e da Natureza alinhandoos à ideia de que são elementos culturais necessários à constituição de todo ser humano. A nosso ver, esse outro olhar para os conhecimentos que compõem os currículos escolares ganham sentido para a aprendizagem do estudante com deficiência e a possibilidade de relacioná-los ao desenvolvimento desses sujeitos.

Nesse sentido, há de se pensar na religação (MORIN, 2005) dos conhecimentos comuns e específicos que sustentam a aprendizagem e desenvolvimento de educandos apoiados pela modalidade de Educação Especial, até porque essa relação é o currículo vivido e praticado pelo aluno no seu percurso de escolarização. A garantia do direito de apropriação do currículo comum e de determinados saberes específicos encontra-se subtendida em vários documentos normativos, como na Lei de Diretrizes e Bases da Educação Nacional nº 9.394/96 e na Política Nacional de Educação Especial em uma perspectiva inclusiva de 2008. A primeira legislação, ao promulgar a Educação como um direito público e subjetivo, permite-nos entender que a apropriação do conhecimento historicamente constituído passa a ser um direito do estudante com deficiência, transtorno global do desenvolvimento e altas habilidades ou superdotação e um compromisso do Estado, já que é a busca pelo conhecimento que leva esses sujeitos à escola. Os conhecimentos específicos, então, no caso, dos alunos público-alvo da Educação Especial, se constituem na, maioria das vezes, em ferramentas para o acesso ao conhecimento socialmente constituído.

Para tanto, essa legislação explicita no Art. 59, o direito de acesso aos currículos escolares, necessitando, as unidades escolares, disponibilizarem métodos, técnicas, recursos educativos e organizações específicas para atender às necessidades de aprendizagem dos educandos. Paralelo a esse movimento, sinaliza, no Art. $4^{\circ}$, inciso III, a garantia do atendimento educacional especializado por reconhecer a necessidade de intervenções mais específicas que perpassam a apropriação do conhecimento por esses sujeitos. Como podemos ver, a articulação entre "conhecimentos comuns e específicos" se configura como uma ação que atravessa e transversaliza o processo de inclusão desses estudantes nas escolas de ensino regular.

Ademais, essa mesma legislação, ao reconhecer a Educação Especial como modalidade de ensino, nos permite entender que ela não substituirá o processo de 
escolarização. A expressão modalidade simboliza colocar os conhecimentos da Educação Especial a serviço da Educação Escolar para apoiar a aprendizagem dos alunos. Mais uma vez, a apropriação do currículo comum se torna uma ação inegável, mesmo naqueles casos em que se coloca como necessária a apropriação de saberes específicos.

Assim, a Educação Especial se afasta da ideia de ser substitutiva - como se configurou no transcorrer da história - para ser assumida como ação que transversaliza todas as etapas, níveis e outras modalidades de ensino. Esse encaminhamento dado à Educação Especial reafirma a obrigatoriedade da oferta de condições para o estudante se apropriar dos conhecimentos historicamente acumulados, pois conforme salienta Saviani (2003, p. 15), “[...] é a exigência de apropriação do conhecimento sistematizado por parte das novas gerações que torna necessária a existência da escola".

A relação entre a apropriação dos conhecimentos comuns e de saberes específicos no processo de escolarização de pessoas com deficiência vem se configurando uma afirmação muito presente nas políticas públicas educacionais. No entanto, nosso olhar para a literatura atual aponta que essa relação pouco se efetivou, mas que se apresenta problemática e desafiadora. Neste artigo, buscaremos evocar possíveis razões para que tenhamos que instituir uma articulação entre tais conhecimentos.

\section{O que nos dizem as políticas nacionais? Uma tensão histórica}

A Política Nacional de Educação Especial em uma perspectiva inclusiva de 2008 também apresenta essa preocupação. O documento traz novos encaminhamentos para a oferta da Educação Especial como modalidade de ensino. Define os estudantes com deficiência, transtornos globais do desenvolvimento e altas habilidades ou superdotação como educandos apoiados pelas políticas de Educação Especial e apresenta novos direcionamentos para a compreensão do atendimento educacional especializado e para a oferta desses serviços.

Ressaltamos a ideia de o documento se preocupar em apontar não somente orientações para a oferta desses serviços, mas também direcionamentos para a 
constituição de um outro sentido para o atendimento educacional especializado, já que a Educação Especial se configurou por longos anos como fundamentada na apropriação de saberes específicos sem conjugá-los a outros conhecimentos necessários ao desenvolvimento de qualquer indivíduo.

\begin{abstract}
A educação especial se organizou tradicionalmente como atendimento educacional especializado substitutivo ao ensino comum, evidenciando diferentes compreensões, terminologias e modalidades que levaram à criação de instituições especializadas, escolas especiais e classes especiais. Essa organização, fundamentada no conceito de normalidade/anormalidade, determina formas de atendimento clínicoterapêuticos fortemente ancorados nos testes psicométricos que, por meio de diagnósticos, definem as práticas escolares para os alunos com deficiência. (BRASIL, 2008, p. 2)
\end{abstract}

Desta forma, na Política Nacional de Educação Especial em uma perspectiva inclusiva, é reafirmado que a escolarização dos estudantes se efetiva na escola de ensino regular e que o atendimento educacional especializado precisa ser assumido como um conjunto de ações que complementam ou suplementam o processo ensinoaprendizagem, nunca substitutivo ao ato educativo desenvolvido pelos professores a partir do currículo comum.

Assim, para que ocorra esse processo de suplementação ou complementação, é necessário pensar no que será complementado/suplementado. Como falamos de processo de escolarização, podemos inferir que o elemento que receberá esses apoios são os currículos escolares por serem os instrumentos que dão base para a formação de todos os estudantes.

Por isso, temos apostado em uma perspectiva de trabalho que leve o atendimento educacional especializado a se aproximar do cotidiano da sala de aula comum para que as ações desses dois ambientes se tornem complementares um ao outro. Uma proposta de atendimento educacional especializado que encontre na sala de aula comum pistas das intervenções a serem realizadas com os alunos. (VIEIRA, 2012, p. 29)

A busca por criar sintonia entre o atendimento e as especificidades de aprendizagem dos estudantes apoiados pela modalidade de Educação Especial também 
se presentifica nos estudos de vários pesquisadores. Kassar e Rebelo (2013), ao historicizarem a incorporação desses serviços no atendimento às pessoas com deficiência, sinalizam que eles sempre se fizeram presente, no entanto, ganhando diferentes enfoques e encaminhamentos no transcorrer da história.

As autoras ressaltam que entre os anos de 1961 e 1971 - período que compreende a promulgação da primeira Lei de Diretrizes e Bases da Educação Nacional n 4.024/61 a Lei $\mathrm{n}^{\circ}$ 5.692/71 (complementar à primeira) - ocorre a inexistência de legislações específicas para a modalidade de Educação Especial. Somente a partir de 1978 que surgem portarias que trazem direcionamentos sobre a oferta de intervenções com estudantes com algum tipo de comprometimento físico, mental e sensorial.

A partir daí, cunha-se o termo atendimento especializado para definir as atividades desenvolvidas para atender às necessidades educacionais especiais de aprendizagem dos estudantes apoiados pela Educação Especial, mesmo assim calcadas em pressupostos de cunho clínico-terapêutico e de modo geral desconectadas da vida escolar. Essas intervenções se realizaram em classes especiais, instituições especializadas, salas de apoio ou de recursos ou ainda em oficinas pedagógicas. O objetivo final desses atendimentos era possibilitar a integração social, já que o estudante precisava se adequar à sociedade e não esta ser repensada para dar conta da diversidade/diferença humana existente.

Os estudos das autoras sinalizam que somente nos meados da década de 1980 que o termo educacional foi incorporado à expressão atendimento especializado e a Educação Especial significada como parte integrante da Educação. Com isso, surgiram expectativas, pois se esperava que o conceito educacional pudesse trazer outras possibilidades de aprendizagem para os estudantes. $\mathrm{O}$ aluno com deficiência continuou sendo significado como não propenso à apropriação do currículo comum e o atendimento educacional especializado como o serviço responsável pelo pleno desenvolvimento desse sujeito.

Neste contexto, colocar a Educação Especial como parte integrante da Educação não significa colocá-la a serviço da Educação, mas criar sistemas de ensino paralelos. Um para os ditos normais e outro para os considerados deficientes. Atribuir ao atendimento educacional especializado a tarefa de promover sozinho o pleno desenvolvimento do 
educando é uma forma de dizer que esse sujeito demanda somente de conhecimentos específicos, mas desconectados de outros saberes e experiências necessários ao desenvolvimento de sua humanidade.

Historicamente o conceito de deficiência é sinônimo de incapacidade e vulnerabilidade. $O$ estigma da inferioridade na relação com pessoas não deficientes acompanha e constitui o imaginário social e institucionaliza práticas sociais que segregam e marginalizam. Com essas representações, a pessoa com deficiência precisa permanentemente provar suas potencialidades. (CAIADO; ZEPPONE, 2013, p. 238)

Como podemos ver, há uma tensão histórica entre a apropriação de conhecimentos comuns e específicos no processo de escolarização de estudantes apoiados pela Educação Especial. Nesse sentido, cabe-nos pensar: o que significa uma tensão? Meirieu (2005, p. 73) nos ajuda a entender o conceito quando afirma que no sentido pedagógico o termo tensão: “[...] é utilizado como metáfora para descrever o estado de um educador que deve fazer frente a exigências contraditórias e não pode - o que seria uma inconsequência - abandonar nenhuma”.

Em nossas palavras, diante da relação entre conhecimentos comuns e específicos no processo de escolarização de estudantes com deficiência, a tensão que se coloca é pensar em uma constituição de complementaridade entre esses dois saberes de modo a romper com hierarquias, supressões e invisibilidades.

\section{Em busca de zonas de inteligibilidade: interrogando as tensões e seus} sentidos

Boaventura de Sousa Santos (2006), em vários de seus estudos, sinaliza que vivemos em uma sociedade marcada pela produção da invisibilidade e negação de muitos conhecimentos e experiências. Isso porque o pensamento moderno é considerado pelo autor como abissal, ou seja, que produz realidades críveis e não críveis. As visíveis são as valoradas pelas classes hegemônicas e capitalistas e as não críveis são aquelas negadas, embora existentes. Nesse sentido, “[...] o primeiro desafio é enfrentar esse desperdício 
de experiências sociais que é o mundo já que temos algumas teorias que nos dizem não haver alternativa, quando na realidade há muitas alternativas (SANTOS, 2006, p. 37).

Acreditamos que essa linha de pensamento tem estreita relação com a tensão existente entre apropriação de conhecimentos comuns e específicos por estudantes apoiados pela modalidade de Educação Especial, principalmente por constituir a ideia de que existem grupos sociais capazes de apreender o que historicamente foi acumulado pela humanidade e outros incapacitados de assim proceder. Desta forma, pessoas com deficiência são consideradas incapazes de aprender e, assim, mediante a existência dessa incapacidade é preciso fazer uma distinção entre os saberes: uns para a manutenção da sociedade, ou seja, para os ditos normais; outros para pessoas com deficiência, visando a sua integração social sem desestabilizar esse contexto.

É justamente a tensão existente entre conhecimentos comuns e específicos que direcionou nosso olhar para o cotidiano de escolas públicas de Ensino Fundamental que vivenciam o desafio de escolarização de estudantes com deficiência, transtornos globais do desenvolvimento e altas habilidades ou superdotação. Essa tensão nos motivou a entender alguns desafios e nós que precisam ser desatados para que esses educandos tenham garantido o direito de apropriação dos conhecimentos historicamente constituídos e dos saberes específicos demandados a partir de suas condições de existência.

Para tanto, nos apoiaremos em discursos produzidos por professores do ensino comum e de Educação Especial que atuam em escolas públicas de Ensino Fundamental da região metropolitana de Vitória - ES sobre o processo de inclusão escolar de estudantes com deficiência. Essas produções estão carregadas de sentidos, pois evidenciam como os profissionais da Educação vêm subjetivando a tensão existente na apropriação de conhecimentos comuns e específicos por educandos apoiados pela modalidade de Educação Especial que, na atualidade, estão matriculados nas escolas de ensino regular.

Ao utilizarmos os discursos dos professores, nos aproximamos do pensamento de Orlandi (1999, p. 17) quando salienta que eles nos permitem perceber a "[...] língua funcionando para a produção de sentidos", pois por meio da linguagem significamos a realidade social e conferimos sentidos para a existência humana. É através do discurso 
que as palavras que dizemos fazem sentido, pois trazem para o debate nossos pontos de vista, nossas concepções, nossas ideias, o significado do que produzimos e do que é produzido ao nosso redor. Esses discursos também são atravessados por outros discursos produzidos no cotidiano social, porque estão recheados dos pensamentos e dizeres de outros sujeitos sociais e por estarem armazenados em nossa memória influenciam os enunciados que produzimos.

O homem se faz na linguagem que o faz. A linguagem está em nós e nós estamos na linguagem. Somos abertos pela linguagem, fechados na linguagem, abertos ao outro pela linguagem (comunicação), fechados ao outro pela linguagem (erro, mentira), abertos às idéias pela linguagem, fechados às idéias pela linguagem. Aberto ao mundo e expulsos do mundo pela linguagem, somos, conforme o nosso destino, fechados pelo que nos abre e abertos pelo que nos fecha. (MORIM, 2005, p. 37)

Assim, o diálogo crítico-reflexivo com os discursos dos professores nos permite apreender as ideologias presentes no pensamento dos educadores, como significam os diferentes percursos de aprendizagem dos estudantes e como, por meio da língua, passam a se significar como professores de sujeitos que demandam apoios da modalidade de Educação Especial, ou seja, que demandam se apropriar de conhecimentos comuns e específicos para sua escolarização.

Para tanto, estivemos atentos às teorizações de Certeau (1994), ao salientar a importância da escuta para a apreensão dos sentidos construídos pelos praticantes da vida cotidiana. Para esse pensador, uma das maiores virtudes a serem desenvolvidas no humano é a sensibilidade da "escuta", pois estabelece proximidade com o outro, desenvolve uma condição de empatia entre as pessoas e encoraja esses indivíduos a se colocarem, atestando a riqueza das palavras pronunciadas.

As retóricas da conversa ordinária são práticas transformadoras de 'situação de palavra', de produções verbais onde o entrelaçamento das posições locutoras instaura um tecido oral sem proprietários individuais, as criações de uma comunicação que não pertence a ninguém. A conversa é um efeito provisório e coletivo de competências na arte de 
manipular 'lugares comuns' e jogar o inevitável dos acontecimentos para torná-los habitáveis. (CERTEAU, 1994, p. 50)

Para Certeau (1994), as narrativas do homem ordinário - cada um de nós - trazem as artes de fazer desse sujeito que estão carregadas de experiências de vida, sentidos, burlas, estratégias e esquemas de sobrevivência. O homem ordinário "[...] joga com esses lances; deles faz outros com esse repertório: conta histórias por sua vez. Re-cita esses gestos táticos" (CERTEAU, 1994, p. 155).

\section{Conversando com os discursos dos professores: reflexão sobre os dados}

Os discursos foram produzidos em momentos de reuniões, palestras e formações, estando neles presentes os autores deste texto. Essas produções foram constituídas no ambiente escolar e na própria universidade, considerando que temos mantido profícuo diálogo com as redes de ensino por meio de pesquisas e formações, situação que favoreceu a coleta dos dados. Os mesmos foram registrados pelos pesquisadores e analisados com objetivo de discutir as inter-relações entre a apropriação do currículo comum e de conhecimentos mais específicos por estudantes apoiados pela modalidade de Educação Especial.

Uma questão que ganha destaque no discurso dos professores é a discussão que permeou toda a construção deste texto: a necessidade de uma relação de complementaridade entre o currículo comum e os conhecimentos específicos no processo de escolarização de estudantes apoiados pela modalidade de Educação Especial.

Morin (2005) afirma a importância de buscarmos pela inteligibilidade entre os saberes e Santos (2006) corrobora esse pensamento dizendo que é preciso que os conhecimentos se traduzam uns nos outros. Que processos são esses? Diriam esses autores que seriam buscar pelas zonas de contato, aproximações, relações de complementaridade, reconhecendo sempre as singularidades de cada saber, e, simultaneamente, seus pontos de convergência. 
O Braille para ele é conhecimento. É importante para ele. A gente pode dizer que é uma necessidade dele, mas só o Braille não é fundamental. Tem o conhecimento da vida que ele precisa adquirir. O Braille só vai fazer sentido para ele se ele puder usá-lo para dar conta de criar sentidos para os conhecimentos da vida que nós produzimos. (PEDAGOGA)

O Braille não é nada mais nada menos que as letras cursivas. Ele, além do Braille, precisa dos conteúdos. O que é o Braille para ele? Ele só vai transferir aqueles conteúdos que ele tem mentalmente em escritos. $O$ Braille é a letra. Então, aprender o Braille é aprender a jogar para o papel o que você tem na cabeça. Ele tem que estar captando tudo, porque só vai fazer sentido o Braille, se ele puder utilizá-lo para dar sentido ao que aprendeu sobre a história do mundo. É a junção desses dois conhecimentos. (PROFESSOR DE EDUCAÇÃO ESPECIAL)

Para tanto, há de se criar contextos de aprendizagem que permitam que o estudante crie sua relação com o conhecimento. Muitas vezes, o que é ensinado nos cotidianos escolares objetiva capacitar os discentes a realizarem tarefas escolares e obterem resultados nos processos de avaliação. Há de se buscar pela implicação do conhecimento no desenvolvimento do humano, por isso Carvalho (2011) afirma que o conhecimento passa a fazer sentido para o aluno quando o afeta. Afeta no sentido de tocá-lo, ajudá-lo a compreender o universo simbólico e as relações que estabelece com o mundo físico e social. É a busca por uma concepção de currículo que toca o estudante que nos faz concordar com Prieto (2009, p. 61) ao dizer que:

[...] resta, então, quase nenhuma alternativa para trabalhar com currículos mais abertos [...], uma das exigências para que as escolas possam atender aos alunos considerando suas características próprias e uma condição indispensável para a escolarização de alguns daqueles que apresentam necessidades educacionais especiais.

Desta forma, a tensão que se desenha não é criar uma relação hierárquica entre o currículo comum e os saberes específicos que atravessam o processo de escolarização de estudantes apoiados pela Educação Especial. A tensão posta é garantir a apropriação desses saberes de forma que o aluno os experimente, lide com eles em sua vida cotidiana e produza as zonas de inteligibilidade. 
A segunda tensão está intimamente relacionada à primeira. Se partirmos do pressuposto que é preciso produzir a tradução dos conhecimentos no processo de escolarização dos alunos apoiados pela modalidade de Educação Especial, é importante que esse mesmo processo se efetive entre a atuação dos profissionais que lidam com esses estudantes.

A Lei de Diretrizes e Bases da Educação Nacional n 9394/96 afirma a participação de professores capacitados e docentes especializados na mediação da escolarização dos alunos. Muitas vezes, o professor do ensino regular sente-se despreparado e incapacitado para lidar com a aprendizagem desse estudante na escola de ensino regular.

É preciso deixar claro que defendemos a importância de investimentos na formação inicial e continuada dos educadores para o trabalho pedagógico com sujeitos que apresentam determinadas especificidades de aprendizagem e que demandam dos serviços da Educação Especial. Mas é preciso também evidenciar que na condição de professores, acumulamos um conjunto de conhecimentos e experiências que podem contribuir com a formação humana e acadêmica dos estudantes.

Muitas vezes, ouvimos discursos: “[...] Minha experiência é trabalhar a alfabetização, no entanto com crianças ditas normais”. Assim, paramos para pensar: A criança com deficiência não precisa se apropriar de sua língua materna para se desenvolver como qualquer outro humano? Há também discursos que sinalizam: “[...] O que fazer com a criança com deficiência na Educação Infantil? Por onde começar?". As Diretrizes Nacionais Curriculares para a Educação Infantil apontam o brincar, o cuidar e o educar como as bases do trabalho pedagógico nesta etapa de ensino. Nesse contexto, cabe-nos refletir: crianças com deficiência não necessitam desses processos?

Dei aula para a turma a partir do currículo que estou acostumado a trabalhar e de que fui formado para explorar com os alunos. Ela fica na sala de aula, mas não acompanha. Eu não sei o que ela pode aprender e o que aprendeu. $O$ trabalho é feito pela Educação Especial. A professora trabalha com atividades mais simples como a alfabetização, a escrita de algumas palavras, com os numerais e o nome dela. Ela tem um caderno, mas não fui eu quem preparou. Decidimos que ela ia passar porque falaram da lei que manda e do laudo, não porque acompanhou 0 currículo. (PROFESSOR DA EDUCAÇÃO BÁSICA - MATEMÁTICA) 
O professor do ensino regular pode perceber fragilidades em sua formação sobre a construção de determinadas metodologias de ensino, uso de recursos e maneiras de lidar com o estudante e de tornar o currículo comum acessível para esse sujeito. Nesse contexto, entra em cena a atuação dos professores especializados que vêm se dedicando a estudar e a criar estratégias para contemplar as necessidades de aprendizagem desses alunos. Por meio de uma ação colaborativa, é possível articular os saberes e experiências desses profissionais e traduzi-los uns nos outros, visando à apropriação do currículo comum e dos saberes específicos, caso seja uma necessidade do aluno.

[... ] quando eu assumi a turma, qual foi a minha preocupação? Leitura e escrita. [...] desde o primeiro dia, meu foco foi leitura e escrita, com todos os alunos. Houve um progresso, porque tinha aluno da $4^{\mathrm{a}}$ serie que não sabia 'b' com ' $a$ '. Todos eles tiveram desenvolvimento no trabalho realizado com esse foco. Uma evolução pequena com certeza, mas é o que estou falando: Lucas, sozinho produzindo frase é um avanço. Não sabia uma sílaba. Isso é um avanço, porque Lucas era uma criança que não conhecia o alfabeto, então esse foi o meu foco. (PROFESSORA)

Como dito, a formação continuada é uma ação necessária. O encontro, a reflexão, a colaboração, o aprender com o outro se configura em um rico contexto de aprendizagem docente. Esse processo não é o único, mas um dentre tantos outros contextos de formação que o professor precisa vivenciar.

[...] sempre se aprende apenas com os outros. É preciso estar 'com os mesmos' para se sentir considerado em suas especificidades, porém mesmo 'com os mesmos', só se aprende 'com os outros' ou, mais exatamente, porque 'os mesmos', em um âmbito considerado, também são 'outros' em um outro domínio... Com o idêntico não se aprende nada: a pessoa sente-se confortável em suas certezas, admira-se como Narciso no espelho do outro, até cair, logo depois, na rivalidade mimética dos 'irmãos inimigos'. (MEIRIEU, 2005, p. 124)

Para a efetivação deste processo, muitos movimentos precisam ser realizados. Dentre eles, a constituição de subjetividades rebeldes (SANTOS, 2007). Para Santos 
(2007), vivemos em um contexto social, político e econômico que deseja despertar em nós subjetividades conformistas. As subjetividades rebeldes são desejos, ideias, posturas, atitudes e ações que assumimos para produzir mudanças em contextos sociais invisibilizados e negados pela sociedade excludente em que vivemos.

Para tanto, é importante que o professor se implique. Ou melhor, que se permita vivenciar essa experiência. Implicar significa enredar, envolver, fazer participar, ser tocado. A implicação abre possibilidades para o professor reconhecer a formação docente como um processo contínuo, a necessária inter-relação entre teoria e prática, a assunção do aluno e do professor como sujeitos de conhecimento, a luta por uma Educação com qualidade e o compromisso do ensino na aprendizagem do estudante por reconhecê-lo como um direito inegável. Tais aspectos têm ecoado em nossos ambientes de pesquisas e temos percebido que, talvez, uma grande diferença é a condição do professor que se implica com o ensinar todos os alunos, pois “[...] implicar-me consiste sempre em reconhecer simultaneamente que eu implico o outro e sou implicado pelo outro na situação interativa" (BARBIER, 2004, p. 101).

A implicação com a aprendizagem do aluno é uma atitude ética e política que atravessa a atuação de todos os profissionais da escola. Essa atitude colabora para que as ações da Educação Especial ganhem potência na escola e passem a transversalizar o processo de inclusão escolar. A implicação possibilita o protagonismo dos professores no ato de ensinar. Nesse sentido, ao discutirmos a tensão entre currículo comum e conhecimentos específicos, percebemos a necessária reflexão: como fazer dialogar os conhecimentos dos professores de sala de aula regular e os conhecimentos dos professores de Educação Especial de forma que eles se traduzam, se impliquem, se complementem e se encontrem para possibilitar ao estudante o direito de aprender? Percebemos que esse diálogo se faz necessário, já que defendemos a ideia de que ambos possuem saberes que contribuem para o processo de aprendizagem dos alunos e para o cumprimento da função social da escola.

Olha, o apoio em sala de aula tem me ajudado muito. Enquanto os alunos fazem as atividades, a professora de Educação Especial vai dando um apoio a eles. Ai pego a meninada especial e vou fazendo as minhas 
tentativas. Trabalhar com a Educação Especial é um desafio, mas acho que, com o apoio, é mais possível. (MARGARIDA - PROFESSORA)

Uma terceira tensão também está relacionada às duas anteriores. Uma vez compreendida a relação entre o currículo comum e os conhecimentos específicos a serem apropriados pelo estudante e o protagonismo dos profissionais da Educação neste processo, sem hierarquias, precisamos buscar conexões entre a sala de aula regular e a de recursos multifuncionais de forma tal que elas se complementem e se traduzam.

[...] crianças, não entrem na sala de recursos porque ela não é nossa. Essa sala é para as crianças especiais. Nossa sala é a outra. A sala que a tia dá aula. (PROFESSORA)

Aqui na escola tem a sala de recursos multifuncionais. Tem muito material interessante lá. Espero que essa mesma atenção seja dada para a sala de aula regular. Precisamos também enriquecer esse ambiente, caso contrário, a gente reforça a ideia de que lá é interessante e aqui não. (PROFESSORA)

A Política Nacional de Educação Especial em uma perspectiva inclusiva (2008), o Decreto 7.611/2011 e a Resolução 4/2009 apontam a instalação de salas de recursos multifuncionais como o espaço-tempo para a oferta do atendimento educacional especializado. Nosso desejo como pesquisadores da modalidade de Educação Especial não é finalizar a oferta desses serviços em um único espaço-tempo, mas entendê-lo como uma rede de apoio que se constitui em todas as ações da escola para apoiar o processo de escolarização do aluno.

Temos apostado em uma perspectiva de trabalho que leve o atendimento educacional especializado a se aproximar do cotidiano da sala de aula comum para que as ações desses dois ambientes se tornem complementares um ao outro. Uma proposta de atendimento educacional especializado que encontre na sala de aula comum pistas das intervenções a serem realizadas com os alunos. Há de se pensar que a mesma especificidade que leva esse indivíduo ao atendimento educacional especializado, também aparece na sala de aula comum, pois não escolarizamos um sujeito 
multifacetado que, em um determinado ambiente, apresenta certa necessidade enquanto essa mesma demanda se apaga em outro. Assim, temos nos desafiado a pensar o impacto dessa especificidade no coletivo da sala de aula comum, não alçando esse ambiente ao lugar de coadjuvante em detrimento dos espaços especializados, mas buscando diálogos para que tanto um espaço quanto o outro protagonizem ações pedagógicas para sustentar os processos de desenvolvimento desses estudantes.

\section{Considerações Finais}

Os diálogos com os sentidos, os pensamentos e as ações produzidos pelos profissionais da Educação proporcionaram reflexões sobre tensões que precisamos assumir para produzir encontros entre o currículo escolar e determinados conhecimentos específicos que atravessam o processo de escolarização de estudantes apoiados pela modalidade de Educação Especial.

A religação dessas tensões pode apontar novas possibilidades de aprendizagem e rompimento com processos de escolarização, muitas vezes, atravessados por diagnósticos clínicos que suplantam as possibilidades de aprendizagem; pela constituição de uma identidade negativa sobre o jeito de ser do aprendiz e pela ideia de que o currículo escolar deve atender a uma condição hegemônica e não ao desenvolvimento do humano.

Finalizamos esse texto com a reflexão de uma professora que, ao discutir a tensão existente nas questões aqui explicitadas, nos convida a pensar em uma outra lógica para a relação existente entre o aluno e o conhecimento. Assim afirma a educadora:

$O$ currículo tem que ser vivo. $O$ aluno tem que se sentir parte do currículo. Muitas vezes, o currículo é dono dele. Ele é que tem que ser dono do currículo. Ele é quem tem que agir sobre o currículo [...]. Eu sou o sujeito da aprendizagem. Não é a folha que me tem. Não é o lápis que me tem, mas sou eu quem tenho a folha e o lápis. Então, o aluno tem que estar agindo sobre o currículo. Ele tem que estar inserido, porque aí faz sentido. Muitas vezes, o conhecimento já vai pronto e, às vezes, aquela não é a necessidade do aluno. Não é o ponto de partida para aquele momento. Pode até ser um ponto de chegada, mas se ele chega pronto, 
já chega determinado. Então o currículo tem que ser construído. Para mim, só assim vamos conseguir dar sentido a ele. (CELINA PROFESSORA DE EDUCAÇÃO ESPECIAL)

Como podemos perceber no transcorrer do texto, tensões se constituem no processo de escolarização dos alunos. Não há como negar um saber em detrimento do outro, nem mesmo invisibilizar a atuação de um profissional mediante a experiência do outro. É importante religar as ações da sala de aula comum e a de recursos multifuncionais, pois essas traduções podem acenar possibilidades para que a escola de ensino regular seja singularizada como um ambiente de bons encontros e ricas aprendizagens (MEIRIEU, 2002).

\section{Referências}

BARBIER, Renné. A pesquisa-ação. Tradução de Lucie Didio. Brasília: Líber Livro Editora, 2004.

BRASIL. Ministério da Educação. Política pública de educação especial na perspectiva da educação inclusiva, 2008. Disponível em:

<http://portal.mec.gov.br/arquivos/pdf/politicaeducespecial.pdf>. Acesso em: 10 mar. 2009.

CAIADO, Kátia Regina Moreno; ZEPPONE, Rosimeire Maria Orlando. Educação e deficiência na voz de quem viveu essa trama: apoios e atendimentos durante a trajetória escolar In: BAPTISTA, Cláudio Roberto; CAIADO, Kátia Regina Moreno; JESUS, Denise Meyrelles de (Org.). Prática pedagógica na educação especial: multiplicidade do atendimento educacional especializado. Araraquara; São Paulo: Junqueira \& Marin 2013. p. $235-251$.

CARVALHO, Janete Magalhães. A razão e os afetos na potencialização de "bons encontros" no currículo escolar: experiências cotidianas. In: FERRAÇO, Carlos Eduardo (Org.). Currículo e educação básica: por entre redes de conhecimento, imagens, narrativas, experiências e devires. Rio de Janeiro: Editora Rovelle, 2011. p. 103-121. CERTEAU, Michel de. A invenção do cotidiano 1: as artes de fazer. Petrópolis, RJ: Vozes, 1994.

GOULART, Cecília. Letramento e modos de ser letrado: discutindo a base teóricometodológica de um estudo. Revista Brasileira de Educação, Rio de Janeiro, v. 11, n. 33, set./dez. 2006. 
KASSAR, Mônica de Carvalho Magalhães; REBELO, Andressa Santos. O "especial” na educação, o atendimento especializado e a educação especial. In: BAPTISTA, Cláudio Roberto; CAIADO, Kátia Regina Moreno; JESUS, Denise Meyrelles de (Org.). Prática pedagógica na educação especial: multiplicidade do atendimento educacional especializado. Araraquara; São Paulo: Junqueira \& Marin 2013. p. 21-42.

MEIRIEU, Philippe. A pedagogia entre o dizer e o fazer: a coragem de recomeçar. Tradução de Fátima Murad. Porto Alegre: Artmed, 2002.

MEIRIEU, Philippe. 0 cotidiano da escola e da sala de aula: o fazer e o compreender. Porto Alegre: Artmed. 2005.

MORIN, Edgar. O método 5: a humanidade da humanidade. Porto Alegre: Sulina, 2005.

ORLANDI, Eni de Lourdes Paccinelli. Análise de Discurso: princípios e procedimentos. Campinas, São Paulo: Pontes, 1999.

PRIETO, Rosângela Gavioli. A educação especial em municípios paulistas: histórias singulares ou tendência unificadora? In: BAPTISTA, Cláudio Roberto; JESUS, Denise Meyrelles de. Avanços em políticas de inclusão: o contexto da educação especial no Brasil e em outros países. Porto Alegre: Mediação, 2009. p. 57-78.

SANTOS, Boaventura de Souza. A gramática do tempo: para uma nova cultura política. São Paulo: Editora Cortez, 2006.

SANTOS, Boaventura de Souza. Renovar a teoria crítica e reinventar a emancipação social. São Paulo: Boitempo, 2007.

SAVIANI, Demerval. Pedagogia histórico-crítica: primeiras aproximações. 8. ed. rev. e ampl. Campinas, SP: Autores Associados, 2003.

VIEIRA, Alexandro Braga. Currículo e Educação Especial: as ações da escola a partir dos diálogos cotidianos. 2012. 326 f.: Tese (Doutorado em Educação). Programa de PósGraduação em Educação. Universidade Federal. do Espírito Santo, Vitória, 2012.

Recebido em: 14/02/2015 Aprovado em: 27/03/2015

Universidade do Estado de Santa Catarina - UDESC Programa de Pós-Graduação em Educação - PPGE Revista Linhas

Volume 16 - Número 31 - Ano 2015 revistalinhas@gmail.com 